\title{
Analysis of HER-2/neu amplification in endometrial carcinoma by chromogenic in situ hybridization. Correlation with fluorescence in situ hybridization, HER-2/neu, p53 and Ki-67 protein expression, and outcome
}

\author{
G Peiró ${ }^{1}$, D Mayr ${ }^{1}$, P Hillemanns ${ }^{2}$, U Löhrs ${ }^{1}$ and J Diebold ${ }^{1}$ \\ ${ }^{1}$ Institute of Pathology and ${ }^{2}$ Department of Gynaecology and Obstetrics, Klinikum Grosshadern, \\ Ludwig-Maximilians University, Munich, München, Germany
}

\begin{abstract}
Fluorescence in situ hybridization (FISH) is the most widely used technique to detect HER-2/neu gene amplification; however, it is only available in some institutions. In contrast, chromogenic in situ hybridization (CISH) can be evaluated by routine light microscopy. In endometrial carcinoma there are few data concerning HER-2/neu status and prognosis. Therefore, we determined HER-2/neu gene status by CISH using a digoxigenin-labelled probe on $\mathbf{6 0}$ formalin-fixed paraffin-embedded endometrial carcinomas. The data were compared with the immunohistochemistry of HER-2/neu (A0485, TAB250), p53, Ki-67, clinicopathological factors, and survival. By conventional light microscopy, HER-2/neu amplification ( $\geqslant 6$ copies $>50 \%$ cancer cells) was detected in $14 \%(8 / 59)$ tumours, HER-2/neu overexpression ( $>10 \%$ cells moderate/strong complete membrane staining) in 22\% (13/60) for A0485, and 18\% (11/60) for TAB250, p53 (>10\% + cells) in $61 \%(36 / 59)$, and $\mathrm{Ki}-67(>50 \%+$ cells) in $\mathbf{5 0 \%}(30 / 60)$. Discordant cases for $\mathrm{CISH}$ and immunohistochemistry, as well as all $(2+)$ were further analysed by FISH (Vysis). Among 10 cases $(2+)$ and not amplified by CISH, two showed lowlevel amplification by FISH. Significant correlation was found between amplification and protein overexpression $(P \leqslant 0.001)$, and a trend with nonendometrioid type, higher grade, and older age. A better outcome (KaplanMeier) was observed for patients with nonamplified (1-5 copies per nucleus) or low-level (6-10 copies) amplification tumours, low Ki-67 expression, age $<50$ years, endometrioid type, low FIGO (International Federation of Obstetrics and Gynaecology) grade and stage, superficial myometrial infiltration, and no lymphvascular invasion $(P \leqslant 0.036)$, but only as a trend for HER-2/neu protein negative $(P=0.13)$. Cox analysis revealed age, FIGO grade and stage, myometrial infiltration, and lymph-vascular invasion to be independent prognostic factors $(P \leqslant 0.05)$, and a trend for HER-2/neu gene copy number $(0.18)$. In endometrial carcinoma, HER-2/neu gene status can be readily assessed by CISH in routine clinical practice, and it gives more prognostic information than HER-2/neu by immunohistochemistry. FISH analysis in $(2+)$ cases but negative by CISH may detect additional tumours with low-level amplification.

Modern Pathology (2004) 17, 277-287, advance online publication, 30 January 2004; doi:10.1038/modpathol.3800006
\end{abstract}

Keywords: HER-2/neu; CISH; FISH; p53; Ki-67; endometrial carcinoma

The human epidermal growth factor receptor-2 (HER-2/neu) gene on 17q21, also known as c-erb $\mathrm{B} 2$, encodes a $185 \mathrm{kda}$ transmembrane glycoprotein with tyrosine kinase activity. ${ }^{1}$ Amplification results

Correspondence: G Peiró, Pathology Department, Hospital General Universitari d'Alacant, C/ Pintor Baeza s/n, 03010-Alacant,

Spain.

E-mail: peiro_glo@gva.es

Presented in part at the 91st USCAP Meeting, Chicago, February 23-March 1, 2002

Received 14 November 2002; revised 23 April 2003; accepted 16 September 2003; published online 30 January 2004 in abnormally large amounts of the nonmutated receptor on the cell surface, leading to autoactivation of the tyrosine kinase domain, activation of signal transduction pathways, cellular proliferation and/or neoplastic transformation. Recently, its involvement in the pathogenesis of a significant number of human tumours has been suggested. ${ }^{2-6}$ Moreover, HER-2/neu has become of special interest due to the reported association with patients' outcome and the potential role for treatment. ${ }^{3,4,7,8}$ The development of a novel therapeutic agent (Herceptin) that directly targets the protein has increased the demand for testing HER-2/neu status. ${ }^{2,9}$ 
Several techniques have been used to detect HER2/neu abnormalities. Analysis of the amount of protein can be accomplished by ELISA, Western blot, Northern blot, or immunohistochemistry, which is the most frequently used. Gene copy number can be evaluated by FISH, PCR, dot-blot hybridization, or Southern blot. ${ }^{5,7,10-13}$ However, the majority of these methods are recommended as complementary to assess gene status in doubtful cases by immunohistochemistry, and they are only available in some laboratories. ${ }^{11,13-15}$ Thus, there is currently a need of new methods for routine clinical practice. Recently, a modification of the FISH technique, the so-called chromogenic in situ hybridization (CISH), has been described by Tanner et al, ${ }^{16}$ which enables the detection of HER-2/neu gene copies with the conventional peroxidase reaction.

Overall, HER-2/neu amplification and/or overexpression detected by any of the above-mentioned methods have been reported in about one-fourth of breast ${ }^{3,11-13}$ and ovarian cancers, ${ }^{2}$ prostate,${ }^{6}$ and lung neoplasias, ${ }^{5}$ among others. In patients with endometrial carcinoma, a consensus with regard to levels, correlation with clinicopathologic factors, and predictive value of HER-2/neu alterations has not been reached. Overexpression has been seen in $4-69 \%$ of the cases. ${ }^{10,17-25}$ Currently, molecular and clinical outcomes studies addressing gene alterations in this neoplasia are limited. ${ }^{10,20,21,23}$

Deregulation of the mechanisms controlling cell proliferation and apoptosis is known to occur in malignant neoplasms. Recent data on p53 and Ki-67, which are involved in these processes, have merged as valuable prognostic tools. ${ }^{26}$

p53 tumour suppressor gene (17p13) encodes a nuclear phosphoprotein that controls the progression of the cell cycle, as well as apoptosis. Alteration either by mutation or/and deletion, leading to intranuclear protein accumulation in the vast majority of the cases, has been detected in over $50 \%$ of tumours. Contribution to neoplastic progression and more aggressive biologic behaviour has been suggested. ${ }^{17,19,24-28}$

$\mathrm{Ki}-67$ protein is present in the nucleus of cells that are actively undergoing proliferation (not in G0 or early G1). ${ }^{29}$ In several neoplasias, the levels of protein expression correlate well with other proliferation markers (eg mitotic count, S-phase, PCNA, cyclin A and B1), tumour growth, ${ }^{17}$ and occasionally with prognosis. ${ }^{28-30}$

We, therefore, studied the amplification status of the HER-2/neu gene by CISH from 60 archival specimens of endometrial carcinoma. The results were compared with the corresponding HER-2/neu (A0485 and TAB250), p53, and Ki-67 protein expression determined by immunohistochemistry, several clinicopathologic factors, and the outcome. In addition, discordant cases by CISH and immunohistochemistry were further analysed by FISH.

\section{Materials and methods}

We selected 60 primary endometrial carcinomas (30 FIGO stage I-II and 30 stage III-IV) treated between 1983 and 1996 at the Department of Gynecology, Grosshadern, University of Munich. All patients underwent a total abdominal hysterectomy. Bilateral salpingo-oophorectomy and lymphadenectomy, as well as postoperative after loading radiotherapy was performed in nearly all patients except those with FIGO stage IA (all histological grades) or FIGO stage IB grade 1. Only patients with papillary serous carcinomas or malignant Müllerian mixed tumours in FIGO stage IB or higher received chemotherapy, usually with platinum containing protocols. Patient ages ranged from 29 to 91 years (mean 60 years).

Endometrioid carcinomas having at least $10 \%$ of another cell type were classified as mixed. ${ }^{31}$ In addition, mixed tumours with more than $50 \%$ of papillary serous carcinoma component were included in the category of pure papillary serous carcinoma. Histologic grade and stage were assigned according to the FIGO criteria. ${ }^{32}$ Follow-up was available in 58 (96.7\%) patients (median 1590 days).

\section{Chromogenic In Situ Hybridization (CISH)}

All haematoxylin and eosin slides were reviewed in each case, and one to two representative tumour tissue blocks were selected for CISH and immunohistochemical analyses.

Sections of $4 \mu \mathrm{m}$ were cut from archival tissue, which had been fixed in buffered formalin and embedded in paraffin. The sections were deparaffinized and pretreated with TRS6 (DAKO) in a microwave oven at $97^{\circ} \mathrm{C}$ for $15 \mathrm{~min}$. After $30 \mathrm{~min}$ at room temperature to cool down, and a brief rinsing with Tris-buffered saline $(0.05 \mathrm{~mol} / \mathrm{l}$ Tris/HCl saline, $\mathrm{pH}$ 7.4-7.6), the slides were incubated with $0.2 \%$ Protease E (Merck) at $37^{\circ} \mathrm{C}$, followed by rinsing with TRIS-buffered saline, $10 \mathrm{~min}$ incubation with $4 \%$ formaldehyde, washing with distilled water, $10 \mathrm{~min}$ with Triethanolamin, fresh rinsing with distilled water, and dehydrating with graded ethanols. The digoxigenin-labelled HER-2/neu probe (doublestranded) (Zymed) was applied onto the slides, covered with coverslips, and denatured at $94^{\circ} \mathrm{C}$ for $3 \mathrm{~min}$. The hybridization was performed overnight at $37^{\circ} \mathrm{C}$. The slides were then washed for $3 \times 5 \mathrm{~min}$ with $2 \times$ standard saline citrate (SSC) at $65^{\circ} \mathrm{C}$, and for $3 \times 5$ min with $0.1 \times$ SSC at $45^{\circ} \mathrm{C}$, followed by a brief rinsing with $0.05 \%$ TRIS-buffered with Brij 35Solution (Merck). Immunodetection was performed by the labelled avidin-biotin complex peroxidase system (Elite kit; Vector Lab.; Burlingame, CA, USA), with antidigoxigenin $(1: 150,1 \mathrm{~h}$; Roche) and fast red (NovaRED; Vector) as a chromogen, according to the manufacturer's instructions. Finally, sections were lightly counterstained with haematoxylin and covered with VectaMount (Vector). 
HER-2/neu gene signals were scored in histological sections, in at least 150 neoplastic cells, using a conventional microscope (Zeiss). Tumours were classified, depending on the number of gene copies in the nuclei, as normal (1-5 copies) and amplified $(\geqslant 6$ copies or when large gene copy clusters were seen in at least $50 \%$ ). In addition, amplified tumours were classified as low-level (6-10 copies) or high level (>10 copies). ${ }^{16}$

\section{FISH}

HER-2/neu probes were purchased from Vysis (Stuttgart-Fasanenhof, Germany). They are dualcolour probes containing a mixture of spectrum orange-labelled HER-2/neu gene (17q11.2-q12) probe, and spectrum green-labelled centromere control for chromosome 17 (17p11.1-q11.1), which allows a simultaneous determination of the gene and chromosome 17 copies.

Tissue sections $4 \mu \mathrm{m}$ were placed onto slides, airdried, and baked overnight at $56^{\circ} \mathrm{C}$. Slides were dewaxed in xylene for $3 \times 10 \mathrm{~min}$, and then immersed in $100 \%$ ethanol for $2 \times 5 \mathrm{~min}$. Air-dried tissue sections were treated in $1 \mathrm{~mol} / \mathrm{l} \mathrm{NaSCN}$, incubated for $30 \mathrm{~min}$ at $80^{\circ} \mathrm{C}$, washed with Aqua bidest, and treated in a pepsine solution $(8 \mathrm{mg} / \mathrm{ml}$ $\mathrm{H}_{2} \mathrm{O}$; $\mathrm{pH}$ 2.0) for $30 \mathrm{~min}$ at $37^{\circ} \mathrm{C}$. Slides were warmed at $80^{\circ} \mathrm{C}$ for $20 \mathrm{~min}$, and between 10 and $20 \mu \mathrm{l}$ of the hybridization mixture (Vysis, Inc) was applied onto the slides, and denaturation was performed at $80^{\circ} \mathrm{C}$ for $10 \mathrm{~min}$. The hybridization was performed overnight at $37^{\circ} \mathrm{C}$ in a moist chamber. Excess of the probes was washed in $0.1 \times$ SCC at $42^{\circ} \mathrm{C} 3 \times 10 \mathrm{~min}$. Nuclei were counterstained with DAPI/Vectashield.

For the scoring, a Zeiss Axioscope fluorescence microscope (Carl Zeiss Inc., Jena, Germany) was used, equipped with a specially designed filter combination for spectrum green and spectrum orange (Vysis, Inc., Downers Grove, IL, USA). Hybridization signals were scored in at least 120 150 intact non-overlapping nuclei. The ratio of HER2/neu signals per nuclei relative to chromosome 17 centromere signals was calculated in order to avoid the contribution of chromosome 17 polysomy. ${ }^{12}$ Ratios $<2$ were considered as no amplification.
Tumours with ratios between 2 and 5 were classified as low-level amplification, and if $>5$ as high-level amplification. ${ }^{16}$

\section{Immunohistochemistry}

Immunohistochemical analyses were performed on $4 \mu \mathrm{m}$ sections according to standard procedures. Table 1 gives the antibodies, clones, sources, pretreatments, methods, working dilutions, and incubation times. HER-2/neu immunostaining was detected with polyclonal (A0485) (DAKO) and a monoclonal antibodies (TAB250) (Zymed), which react against the HER-2/neu oncoprotein in the cell membrane; p53 (DAKO) antibody recognizes an epitope in the $\mathrm{N}$-terminus of the human p53 protein (both wild-type and mutant); and MIB-1 (Dianova) is a monoclonal antibody that reacts against the intranuclear antigen Ki-67 present in all active phases of the cell cycle.

After pretreatment (see Table 1) the slides were rinsed in TRIS-buffered saline $(0.05 \mathrm{~mol} / \mathrm{l}$ Tris/HCl saline, $\mathrm{pH}$ 7.4-7.6) for $2 \times 5$ min. Endogenous peroxidase activity was blocked by incubation with $10 \%$ $\mathrm{H}_{2} \mathrm{O}_{2}$ for $10 \mathrm{~min}$, followed by $10 \mathrm{~min}$ in water. Sections were immersed in Tris-buffered saline for $2 \times 5 \mathrm{~min}$. The primary antibodies were visualized using the LSAB system (DAKO LSAB kit; Dako Corp.) for A0485, TAB250, and p53; and the alkaline phosphatase-antialkaline phosphatase system (DAKO; Glostrup, Denmark) for MIB-1. In negative controls, the first antibody was omitted. After a brief rinsing in $0.05 \%$ Tris-buffered in 35-Brij Solution (Merck), sections were immersed in 3-amino-9-ethylcarbazole substrate (Sigma) for $15 \mathrm{~min}$, and then lightly counterstained with haematoxylin and coverslipped with Glycergel (Merck, Darmstadt, Germany).

\section{Interpretation of Immunohistochemical Staining}

Immunostaining for HER-2/neu protein (A0485 and TAB250) was observed in the membrane and occasionally in the cytoplasm. Only membranous staining was scored according to the criteria given by the manufacturer (DAKO HercepTest) as follows:

Table 1 Immunohistochemical data

\begin{tabular}{lllllll}
\hline Antibody & Clone & Vendor & Pretreatment & Method & Dilution & Incubat (h) \\
\hline HER-2/neu & A0485 & DAKO & TRS9 in MW & LSAB & $1: 1000$ \\
HER-2/neu & TAB250 $^{\mathrm{b}}$ & Zymed & Ficin Digest-All & LSAB & $1: 300$ & 1 \\
Ki-67 & MIB-1 $^{\mathrm{b}}$ & Dianova & TRS6 in MW & APAAP & $1: 50$ & 1 \\
P53 & DO-7 & DAKO & TRS6 in MW & LSAB & $1: 30$ & 1 \\
& & & & & 1 \\
\hline
\end{tabular}

DAKO, Glostrup, Denmark; Zymed, San Francisco, CA; Dianova, Hamburg, Germany; TRS9, target retrieval sol high pH; DAKO, Carpintería, CA; Ficin Digest-All, Zymed Lab Inc South San Francisco, CA; TRS6, Target Retrieval Sol $10 \times$ concentrate; DAKO, Carpintería, CA; MW, microwave; Incubat, incubation.

apolyclonal.

bMonoclonal. 
positive staining was considered when at least $10 \%$ of neoplastic cells showed complete membrane staining, either weak/moderate $(2+)$ or strong $(3+)$. A negative score was given when focal $(<10 \%)$, and/or faint $(1+)$, or absent $(0)$.

We used the hot spot method (the area with the most intense staining) for Ki-67, according to the approach of previous studies. ${ }^{28}$ We scored the percentage of positive nuclei in approximately 1000 neoplastic cells per slide, subdivided in 10 randomly chosen fields, at $\times 400$ magnification . Three groups were classified as follows: absence or negative $(<10 \%)$, low (10-50\%), and high $(>50 \%)$ protein levels. A simple dichotomous scoring system was used for p53: a cutoff value of $10 \%$ nuclear staining was chosen to separate the negative (normal) from the positive (abnormal/overexpression). Intensity was not taken into account for the scoring, since the majority of the cases stained strongly.

As positive control slides, neoplastic breast tissue known to be positive for the expression of HER-2/neu, p53, or Ki-67 proteins was used. Specimens in which tumour cells as well as normal control cells were completely negative were excluded from the analysis.

\section{Statistical Analyses}

Associations between the expression of the different proteins and several clinicopathologic features were calculated using the $\chi^{2}$ test or Fisher's exact test, as appropriate. Survival curves were plotted using the Kaplan-Meier method, and log-rank tests were performed to determine statistical differences between life tables.

A Cox proportional hazard model was used to asses the effect of the several tumour variables on overall survival. For all calculations, SPSS-10 statistical software (SPSS Inc., Chicago, IL, USA) was used. The level of significance was set at 0.05.

\section{Results}

Table 2 shows the correlation between clinicopathologic factors, CISH, and immunohistochemical data. Immunohistochemical results were scored independently by two pathologists (DM and GP). All discordant cases were restained (either by CISH or immunohistochemistry) and reviewed together to reach an agreement.

Table 2 Correlation between clinicopathological features, CISH, and immunohistochemistry

\begin{tabular}{|c|c|c|c|c|c|}
\hline & $\begin{array}{l}\text { HER- } 2 / \text { neu } \\
(C I S H)^{a}(\%) \\
(1-5 / \geqslant 6 \text { copies })\end{array}$ & $\begin{array}{l}\text { HER-2/neu } \\
\text { (A0405) (\%) } \\
\text { (neg/pos) }\end{array}$ & $\begin{array}{l}\text { HER-2/neu } \\
\text { (TAB-250) (\%) } \\
\text { (neg/pos) }\end{array}$ & $\begin{array}{l}p 53(\%) \\
(<10 \% />10 \%)\end{array}$ & $\begin{array}{l}\text { Ki-67 (\%) } \\
(<50 \% />50 \%)\end{array}$ \\
\hline Total \% & $86 / 14$ & $78 / 22$ & $82 / 18$ & $39 / 61$ & $50 / 50$ \\
\hline \multicolumn{6}{|l|}{ Age } \\
\hline$<50$ years $(n=19)$ & $95 / 5$ & $89 / 11$ & $79 / 21$ & $39 / 61$ & $79 / 21$ \\
\hline$>50$ years $(n=41)$ & $\begin{array}{l}82 / 18 \\
(P=0.2)\end{array}$ & $\begin{array}{l}73 / 27 \\
(P=0.15)\end{array}$ & $\begin{array}{l}78 / 22 \\
(P=\mathrm{NS})\end{array}$ & $\begin{array}{l}39 / 61 \\
(P=\mathrm{NS})\end{array}$ & $\begin{array}{l}37 / 63 \\
(P=0.002)\end{array}$ \\
\hline \multicolumn{6}{|l|}{ Histology } \\
\hline Endom $(n=45)$ & $91 / 9$ & $82 / 18$ & $87 / 13$ & $41 / 59$ & $56 / 44$ \\
\hline Non-end $(n=15)$ & $\begin{array}{l}73 / 27 \\
(P=0.08)>\end{array}$ & $\begin{array}{l}67 / 33 \\
(P=0.2)\end{array}$ & $\begin{array}{l}67 / 33 \\
(P=0.083)\end{array}$ & $\begin{array}{l}33 / 67 \\
(P=\mathrm{NS})\end{array}$ & $\begin{array}{l}33 / 67 \\
(P=0.13)\end{array}$ \\
\hline \multicolumn{6}{|l|}{ Grade } \\
\hline $1(n=9)$ & $89 / 11$ & $89 / 11$ & $89 / 11$ & $50 / 50$ & $56 / 44$ \\
\hline $2(n=22)$ & $95 / 5$ & $91 / 9$ & $91 / 9$ & $50 / 50$ & $73 / 27$ \\
\hline $3(n=29)$ & $\begin{array}{l}79 / 21 \\
(P=0.2)\end{array}$ & $\begin{array}{l}65 / 35 \\
(P=0.06)\end{array}$ & $\begin{array}{l}72 / 28 \\
(P=0.19)\end{array}$ & $\begin{array}{l}28 / 72 \\
(P=0.2)\end{array}$ & $\begin{array}{l}31 / 69 \\
(P=0.012)\end{array}$ \\
\hline \multicolumn{6}{|l|}{ Stage } \\
\hline I-II $(n=30)$ & $83 / 17$ & $77 / 23$ & $80 / 20$ & $53 / 47$ & $63 / 37$ \\
\hline III-IV $(n=30)$ & $\begin{array}{l}90 / 10 \\
(P=\mathrm{NS})\end{array}$ & $\begin{array}{l}80 / 20 \\
(P=\mathrm{NS})\end{array}$ & $\begin{array}{l}83 / 17 \\
(P=\mathrm{NS})\end{array}$ & $\begin{array}{l}24 / 76 \\
(P=0.022)\end{array}$ & $\begin{array}{l}37 / 63 \\
(P=0.039)\end{array}$ \\
\hline \multicolumn{6}{|l|}{ Myom invas } \\
\hline$<50 \%(n=32)$ & $87 / 13$ & $84 / 16$ & $84 / 16$ & $47 / 53$ & $69 / 31$ \\
\hline$>50 \%(n=24)$ & $\begin{array}{l}83 / 17 \\
(P=\mathrm{NS})\end{array}$ & $\begin{array}{l}71 / 29 \\
(P=\mathrm{NS})\end{array}$ & $\begin{array}{l}75 / 25 \\
(P=\mathrm{NS})\end{array}$ & $\begin{array}{l}35 / 65 \\
(P=\mathrm{NS})\end{array}$ & $\begin{array}{l}33 / 67 \\
(P=0.009)\end{array}$ \\
\hline \multicolumn{6}{|l|}{$L V I$} \\
\hline ND/no $(n=29)$ & $90 / 10$ & $90 / 10$ & $90 / 10$ & $39 / 61$ & $59 / 41$ \\
\hline Present $(n=31)$ & $\begin{array}{l}83 / 17 \\
(P=\mathrm{NS})\end{array}$ & $\begin{array}{l}68 / 62 \\
(P=0.04)\end{array}$ & $\begin{array}{l}74 / 26 \\
(P=0.12)\end{array}$ & $\begin{array}{l}39 / 61 \\
(P=\mathrm{NS})\end{array}$ & $\begin{array}{l}42 / 58 \\
(P=0.19)\end{array}$ \\
\hline
\end{tabular}

${ }^{\mathrm{a}} \mathrm{CISH}=$ chromogenic in situ hybridization; Endom= endometrioid type; neg= negative; pos= positive (moderate/strong membrane staining $\geqslant 10 \%$ of tumour cells); myom invas= myometrial invasion; NS= not significant; LVI= lymph-vascular invasion; ND= non definitive. 
Tumours were classified into two groups: (1) endometrioid type (41 pure endometrioid, one mixed endometrioid and mucinous, one mixed endometrioid and secretory, and two mixed malignant Müllerian tumours owing to the presence of endometrioid characteristics $(45 / 60 ; 75 \%)$ ) and (2) special variants (12 papillary serous carcinomas, one clear-cell carcinoma, one mixed clear-cell and endometrioid carcinoma, and one mixed papillary serous and clear-cell carcinoma (15/60; 25\%)). Grade 1 was given in $15 \%(n=9)$, grade 2 in $37 \%$ $(n=22)$, and grade 3 in $48 \%(n=29)$. In all, 30 patients were in low FIGO stage $(43 \%(n=26)$ in stage $\mathrm{I}$, and $7 \%(n=4)$ in stage II), and 30 in advanced stage $(32 \%(n=19)$ in stage III; and $18 \%$ $(n=11)$ in stage IV). Myometrial invasion in $>50 \%$ of the wall was seen in $43 \%(24 / 60)$, and presence of lymph-vascular invasion in 52\% (31/60). Patients' age was $>50$ years in $68 \%$ (mean 60 years).

\section{HER-2/neu Gene Status}

Using a standard light microscope, satisfactory analysis of HER-2/neu gene by CISH was possible in $59(98.3 \%)$. specimens. Although with this technique a semiquantitative evaluation of the signals could be easily performed, we enumerated neoplastic nuclei (in at least 120), following the methodology of previous studies. In all cases with available adjacent endometrium for the evaluation, the gene copy number was normal in the glands, as well as in the stromal cells. In 51 (86\%) tumours, the gene copy number of the neoplastic cells was normal, and in eight $(14 \%)$ tumours amplification ( $\geqslant 6$ copies in $>50 \%$ of cancer cells) was detected. Among amplified tumours, five contained $>10$ copies in $>50 \%$ of cancer cells (Figure 1a).

We observed only a trend of correlation between gene amplification (by CISH) and nonendometrioid type $(4 / 15 ; 27 \% ; P=0.08)$, grade 3 tumours $(6 / 29$; $21 \% ; P=0.2)$, and older age $(7 / 40 ; 18 \% ; P=0.2)$ (See Table 2).

\section{Protein Expression of HER-2/neu (A0485 and TAB250)}

Overexpression of HER-2/neu ( $>10 \%$ + cells with moderate or strong complete membrane staining) was seen in $22 \%(13 / 60)$ for A0485, and 18\% (11/60) for TAB250 (Figure 1b). Occasionally, we observed scattered and light positivity in normal endometrial or stromal cells. A highly significant correlation was found between HER-2/neu protein levels detected
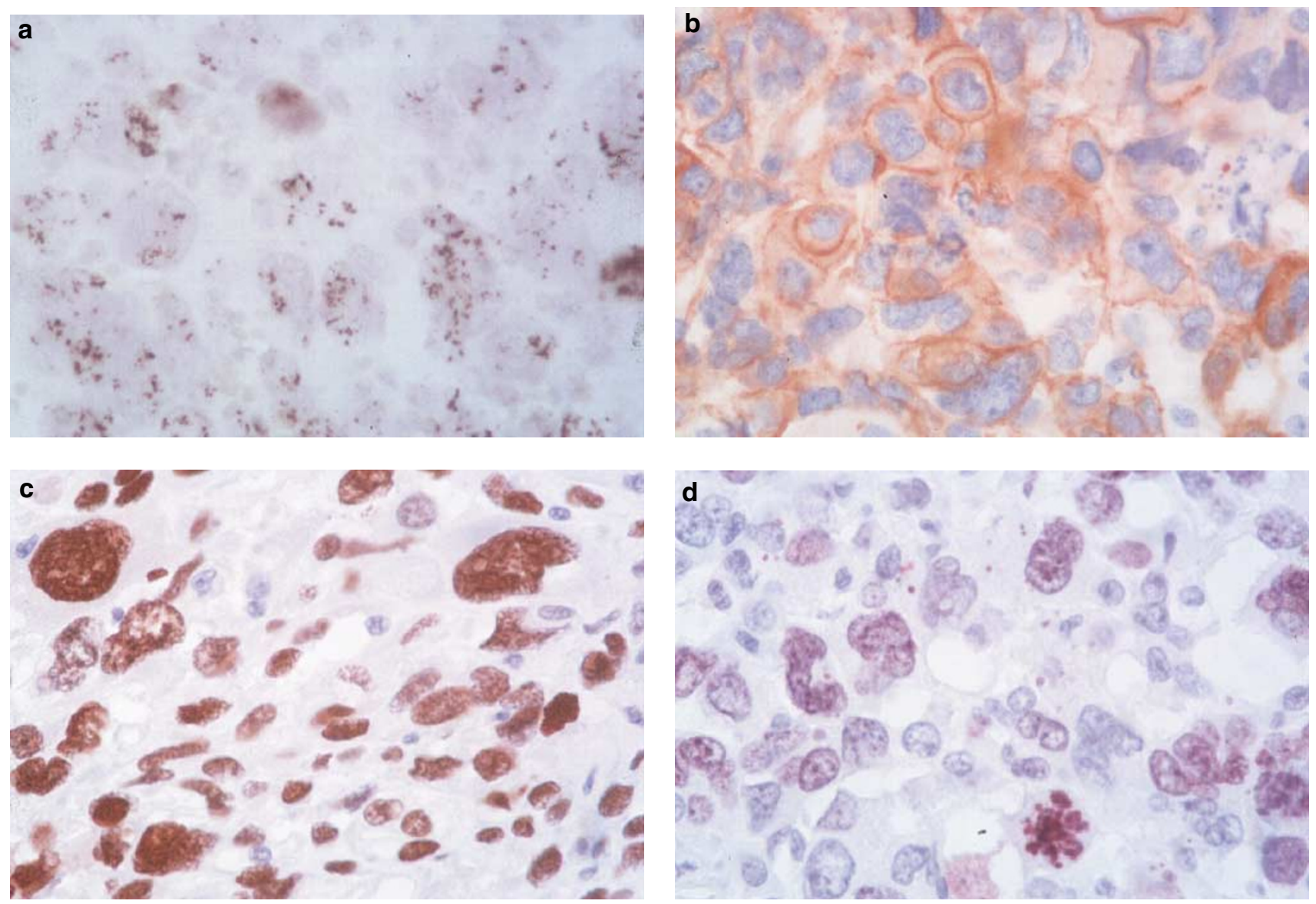

Figure 1 Poorly differentiated endometrioid carcinoma showing (a) HER-2/neu gene amplification (>10 copies/nuclei; CISH), (b) HER2/neu overexpression (A0485), (c) p53 accumulation ( $>10 \%+$ cells), and (d) Ki-67 overexpression ( $>50 \%+$ cells). 
by A0405 and TAB250: 45 cases were negative and nine positive by both antibodies (90\%). Six (10\%) were discordant: four positive by A0485 and negative by TAB250; and two negative by A0485 that were positive by TAB250 $(P<0.0001)$.

HER-2/neu (A0485) overexpression correlated significantly with the presence of lymph-vascular invasion $(10 / 31 ; 32 \% ; P=0.04)$, but only as a trend with older age of the patients ( $>50$ years) $(11 / 41$; $27 \% ; P=0.15)$, nonendometrioid $(5 / 15 ; 33 \%)$ vs endometrioid type $(8 / 45 ; 18 \%)(P=0.2)$, and FIGO grade $3(10 / 29 ; 35 \% ; P=0.06)$. Regarding HER-2/ neu by TAB250, also a trend was seen towards older age $(9 / 41 ; 22 \% ; P=0.2)$, nonendometrioid $(5 / 15$; $33 \%)$ vs endometrioid type $(6 / 45 ; 13 \%)(P=0.083)$, FIGO grade $3(8 / 29 ; 28 \% ; P=0.19)$, and presence of lymph-vascular invasion $(8 / 31 ; 26 \% ; P=0.12)$.

\section{Comparison of HER-2/neu Gene Amplification with Protein Expression}

Table 3 shows the distribution of the results with respect to gene copy number and protein expression for HER-2/neu. Adjacent endometrium and stromal cells contained one to five copies, regardless of the occasional finding of scattered and light immunostaining. HER-2/neu overexpression detected by A0485 correlated better with gene amplification $(7 / 8 ; 88 \% ; P<0.0001)$ than by TAB250 $(5 / 8 ; 63 \%$; $P=0.001)$. In $88 \%$ of the cases $(n=52 ; 45$ negative and seven positive) CISH and A0485 staining results were concordant. Seven (12\%) showed discordance: one case with low-level amplification was completely negative for antibody staining, but six nonamplified cases were considered positive (four tumours were $2+$, and two tumours $3+$ ). Concordance between CISH and TAB250 results was observed in $50(85 \%)$ cases: 45 were negative and five positive by both techniques. Among the nine discordant cases $(15 \%)$, six were nonamplified but the protein was detected $(2+)$; and three amplified cases (two low and one high amplification) showed no protein expression. TAB250 missed more amplified tumours (3/8) than A0485.

All cases with discordant results for CISH and immunohistochemistry, as well as all cases with $(2+)$ HER-2/neu overexpression (either by A0485 or TAB25), were further analysed by FISH $(n=11)$ (see

Table 3 Correlation between CISH and immunohistochemical results

\begin{tabular}{lccccccc}
\hline CISH & $\begin{array}{c}\text { A0485 } \\
(0-1+)\end{array}$ & $\begin{array}{c}\text { TAB250 } \\
(0-1+)\end{array}$ & $\begin{array}{c}\text { A0485 } \\
(2+)\end{array}$ & $\begin{array}{c}\text { TAB250 } \\
(2+)\end{array}$ & $\begin{array}{c}\text { A0485 } \\
(3+)\end{array}$ & $\begin{array}{c}\text { TAB250 } \\
(3+)\end{array}$ & Total \\
\hline $1-5$ & 45 & 45 & 4 & 6 & 2 & 0 & 51 \\
$6-10$ & 1 & 2 & 1 & 0 & 1 & 1 & 3 \\
$>10$ & 0 & 1 & 1 & 1 & 4 & 3 & 5 \\
Total & 46 & 48 & 6 & 7 & 7 & 4 & 59 \\
\hline
\end{tabular}

Table 4). Among the $10(2+)$ tumours, three showed amplification by CISH and FISH. An additional two cases with low-level amplification (ratio 2:5) were detected by FISH, both of nonendometrioid type (papillary serous carcinomas), grade 3 , lymph-vascular invasion present, deep myometrial wall infiltration, and patients' age $>50$ years (see Table 5).

Overall, in the present series we detected amplification (by CISH and FISH) in $17 \%$ (10 of 59 tumours). It was more frequently found in nonendometrioid tumours $(6 / 15 ; 40 \% ; P=0.006)$, grade 3 $(8 / 29 ; 28 \% ; P=0.074)$, presence of lymph-vascular invasion $(7 / 30 ; 23 \% ; P=0.18)$, and older patients $(9 / 40 ; 23 \% ; P=0.09)$ (see Tables 2 and 5$)$. Six cases were classified as false positive by immunohistochemistry. In contrast, one amplified tumour by both assays was immunohistochemically negative (false negative).

\section{Protein Expression of p53 and Ki-67}

p53 analysis was satisfactory in 59 tumours. No immunostaining was detected in normal tissues. p53 accumulation ( $>10 \%+$ cells) was detected in $61 \%(36 / 59)$ (Table 2 and Figure 1c). It was found more frequently in tumours in FIGO stage III-IV than in those in early stage (I-II) $(22 / 29,76 \% ; 14 / 30$, $47 \%$; respectively; $P=0.022$ ). Although higher levels of p53 protein were more common in nonendometrioid tumours (67 vs 59\%), grade 3 (72 vs $50 \%$ ), and with deeper invasion of the myometrial wall (65 vs $53 \%$ ), the results did not reach statistical significance (all $P=n s$ ).

Ki-67 overexpression ( $>50 \%+$ cells) in 50\% (30/ 60 ) of the cases (Figure 1d) was found in tumours of older patients $(26 / 41 ; 63 \% ; P=0.002)$, high grade (20/29; 69\%; $P=0.012$ ), in advanced stage (FIGO III-IV) $(19 / 30 ; 63 \% ; P=0.039)$, and $>50 \%$ invasion of the myometrial wall $(16 / 24 ; 67 \% ; P=0.009)$, and as a trend with nonendometrioid type $(10 / 15 ; 67 \%$; $P=0.13)$.

Tumours with p53 accumulation also showed higher levels of Ki-67 $(P=0.01)$, but no significant

Table 4 Discordant cases for immunohistochemistry and CISH, further analysed by FISH

\begin{tabular}{rccll}
\hline Case \# & A0485 & TAB250 & CISH & FISH \\
\hline 3 & $2+$ & $1+$ & Nonamplified & Nonamplified \\
14 & 0 & 0 & Amplified & Amplified \\
20 & $2+$ & 0 & Amplified & Amplified \\
22 & $2+$ & $2+$ & Amplified & Amplified \\
27 & $3+$ & $2+$ & Nonamplified & Nonamplified \\
36 & $2+$ & $2+$ & Nonamplified & Nonamplified \\
38 & $3+$ & $2+$ & Nonamplified & Amplified \\
40 & $2+$ & $2+$ & Nonamplified & Nonamplified \\
45 & $1+$ & $2+$ & Nonamplified & Nonamplified \\
48 & $1+$ & $2+$ & Nonamplified & Amplified \\
52 & $2+$ & $1+$ & Nonamplified & Nonamplified
\end{tabular}


Table 5 Clinicopathologic features of the amplified tumours either by CISH or FISH ${ }^{\mathrm{a}}$

\begin{tabular}{|c|c|c|c|c|c|c|c|c|}
\hline Case \# & $\begin{array}{l}\text { Copy number } \\
\text { or ratio }\end{array}$ & Age & Histology & Grade & Stage & Myom invasion & $L V I$ & $\begin{array}{l}\text { Survival } \\
\text { status }\end{array}$ \\
\hline 11 & $>10 \mathrm{c} / \mathrm{n}$ & 66 & Endom & 2 & Ia & $<50 \%$ & Present & Dead \\
\hline 14 & $6-10 \mathrm{c} / \mathrm{n}$ & 44 & Endom & 1 & $\mathrm{Ib}$ & $<50 \%$ & No/ND & Alive \\
\hline 20 & $6-10 \mathrm{c} / \mathrm{n}$ & 67 & PSC & 3 & IIIC & $>50 \%$ & Present & Dead \\
\hline 22 & $>10 \mathrm{c} / \mathrm{n}$ & 77 & Clear cell & 3 & Ia & $<50 \%$ & No/ND & Dead \\
\hline $38^{\mathrm{a}}$ & $>2^{\mathrm{a}}$ & 62 & PSC & 3 & IIIa & $>50 \%$ & Present & Dead \\
\hline 42 & $>10 \mathrm{c} / \mathrm{n}$ & 80 & Endom & 3 & IIIC & $>50 \%$ & Present & Dead \\
\hline $48^{\mathrm{a}}$ & $>2^{\mathrm{a}}$ & 65 & PSC & 3 & IIIa & $>50 \%$ & Present & Dead \\
\hline 51 & $6-10 \mathrm{c} / \mathrm{n}$ & 61 & PSC & 3 & $\mathrm{Ib}$ & $<50 \%$ & No/ND & Dead \\
\hline 53 & $>10 \mathrm{c} / \mathrm{n}$ & 63 & Endom & 3 & Ic & $>50 \%$ & Present & Dead \\
\hline 60 & $>10 \mathrm{c} / \mathrm{n}$ & 71 & PSC & 3 & IIIC & $>50 \%$ & Present & Dead \\
\hline$P$-value & / & 0.09 & 0.006 & 0.074 & 0.95 & 0.24 & 0.18 & 0.032 \\
\hline
\end{tabular}

aRatio of HER-2/neu signals per nuclei relative to chromosome 17 signals for FISH.

$\mathrm{c} / \mathrm{n}=$ gene copies per nuclei for CISH; Endom= endometrioid carcinoma; PSC= papillary serous carcinoma; myom= myometrial invasion; $\mathrm{LVI}=$ Lymph-vascular invasion; ND= nondefinitive.

correlation was seen with HER-2/neu expression either assessed by A0485 or TAB250 $(P=n s)$.

\section{Survival Analyses}

Better outcome (Kaplan-Meier; log-rank) was observed for patients with nonamplified tumours by CISH ( $44 \%$ were alive at the last follow-up) or low-level amplification (six to 10 copies) $(33 \%)$, compared with patients with highly amplified ( $>10$ copies) tumours $(0 \%) \quad(P=0.036)$. Analysis of the combined CISH and FISH $(n=10)$ showed similar results $(45 \%$ of the patients with nonamplified tumours alive vs $10 \%$ with amplified tumours; $P=0.032$ ) (Figure 2a). The data were further stratified according to clinicopathologic factors. The results showed that patients with amplified tumours had shorter survival compared with nonamplified tumours, among those in FIGO stage I-II $(1 / 5,20$ vs 15/24, 66\%) and stage III-IV $(0 / 5,0$ vs $7 / 24,29 \%)(P=0.011)$ (Figure $2 b$ and c); and for superficial myometrial invasion (1/4, 25 vs 17/27, 63\%) or deep invasion (0/6, 0 vs 4/17, $24 \%)(P=0.047)$ (Figure $2 \mathrm{~d}$ and e). However, only a trend was observed for lymph-vascular invasion negative/nondefinitive $(1 / 3,33$ vs $14 / 26,54 \%)$ or present $(8 / 22,36$ vs $0 / 7,0 \%)(P=0.10)$; endometrioid (1/4, 25 vs 20/44, 48\%) and nonendometrioidtype carcinomas $(0 / 6,0$, vs $3 / 8,38 \%)(P=0.25)$; and for FIGO grade $1(1 / 1,100$ vs $2 / 8,75 \%)$, grade $2(0 / 1$, 0 vs $10 / 20,50 \%)$ or grade $3(0 / 8,0$ vs $6 / 20,30 \%)$ $(P=0.41)$.

In addition, longer survival was seen for patients younger than 50 years $(P=0.0001)$, endometrioid histology $(P=0.024)$, low FIGO grade $(P=0.0002)$ and stage $(P=0.0002)$, superficial myometrial infiltration $(P<0.0001)$, no lymph-vascular invasion $(P=0.0058)$, and with low levels $(<50 \%$ positive cells) of Ki-67 protein expression $(P=0.01)$ (Figure 2f). However, only a correlative trend was observed with lack of HER-2/neu protein, either for A0485
$(P=0.14)$ or for TAB250 $(P=0.13)$, and no correlation was seen for p53 $(P=n s)$.

Cox analysis revealed age $(P<0.0001)$, FIGO grade $(P=0.004)$ and stage $(P=0.034)$, myometrial infiltration $(P<0.0001)$, and presence of lymph-vascular invasion $(P=0.05)$ to be independent predictors of prognosis. Regarding HER-2/neu gene copy number, we observed still a trend either for the data obtained by CISH $(P=0.12)$ or including the additional cases by FISH $(P=0.18)$.

\section{Discussion}

In endometrial carcinoma, conventional clinicopathological factors such as FIGO grade and stage, histologic type, lymph-vascular invasion, or depth of myometrial invasion are well-known predictors of prognosis. However, identification of molecular genetic alterations that could add relevant prognostic information to the traditional factors has become one of the goals of recent research in this and other neoplasias. ${ }^{25,28}$

The involvement of HER-2/neu gene has been suggested in several human neoplasias, and it is thought to influence the responsiveness to cytotoxic chemotherapy and prognosis. ${ }^{2,8}$ Several methods have been proved to be useful for the assessment of HER-2/ neu status. ${ }^{4,5,7,10-13}$ Nevertheless, considerable confusion exists with regard to the appropriate method and reagent for testing it in routine clinical practice. ${ }^{7}$ Furthermore, most of the methods are beyond the scope of the majority of pathology laboratories due to technical, practical, and economical reasons. ${ }^{11}$ Immunohistochemistry is the most widely available method due to its relatively low cost, and it is rapid, easy to perform, and evaluate. However, the accuracy of the results is still questionable. ${ }^{9}$

In endometrial carcinoma, immunohistochemical or molecular studies addressing the HER-2/neu protein or gene status, and the prognostic utility of these alterations are limited. In our series, we 

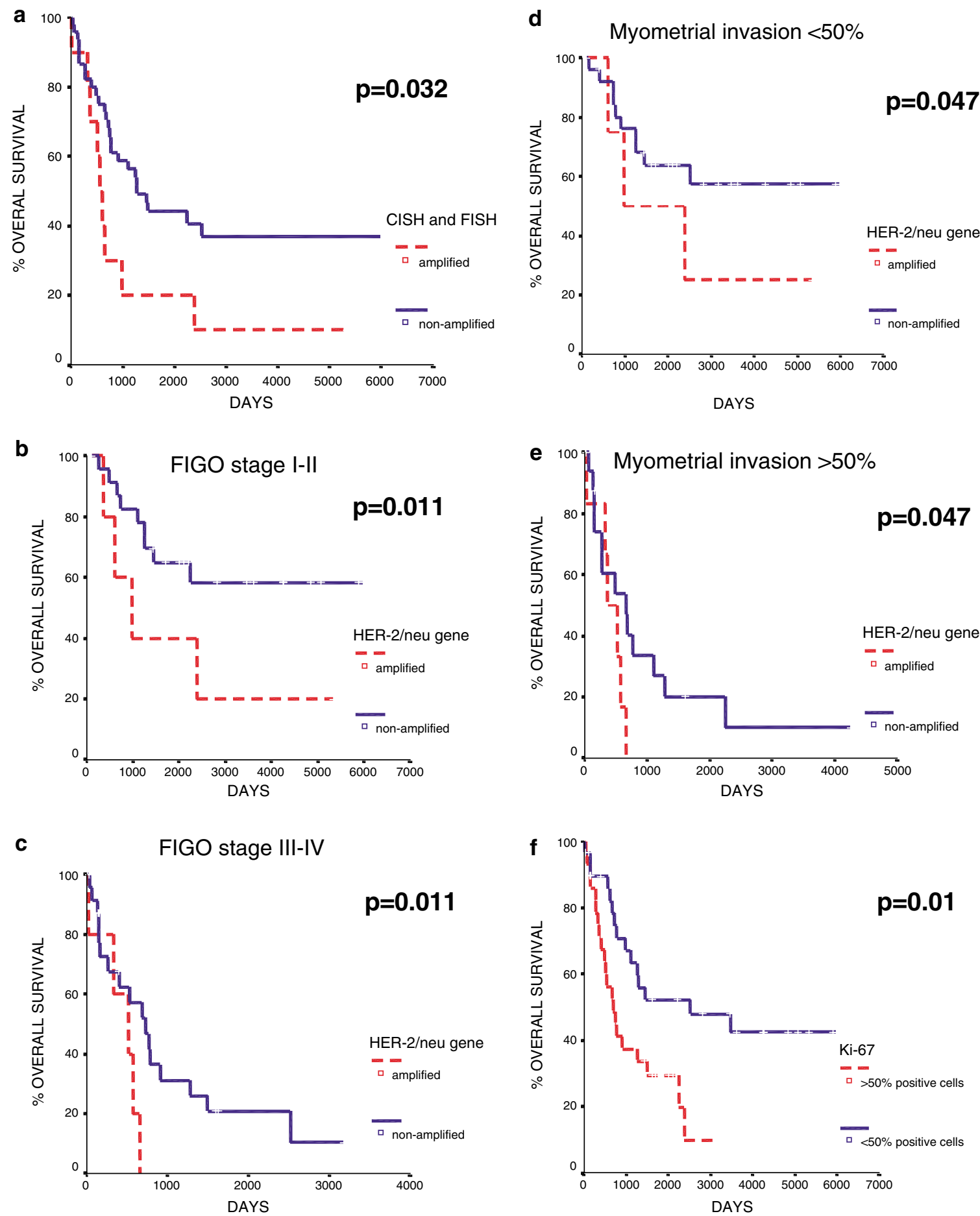

Figure 2 Survival curves (univariate analysis-log rank test) for (a) HER-2/neu gene copy number (CISH and FISH amplified tumours), data stratified by FIGO stage (b and $\mathbf{c}$ ), and myometrial invasion (d and $\mathbf{e}$ ); and (f) survival for Ki-67 protein expression.

observed overexpression in $22 \%$ of the tumours by A0485 (polyclonal) and in 18\% by TAB250 (monoclonal), which are in the lower range reported by other authors (4-69\%). This wide variation may be at least in part related to inherent differences of material, as well as antibodies clones, methods of detection, and nonuniform scoring systems among the studies. ${ }^{10,18-25}$
HER-2/neu overexpression is thought to be the result of gene amplification. ${ }^{2}$ FISH analysis, seen as a gold standard method for detecting gene amplification, is considered to be more accurate and quantitatively precise than immunohistochemistry. However, correlation with tissue morphology is difficult due to dark-field visualization, it is time consuming, technically demanding, and more 
expensive because of the requirement of sophisticated equipment. Thus, it is not considered very practical for routine histopathological laboratories. ${ }^{11,15}$ In contrast, CISH is a new technology that makes the assessment of HER-2/neu gene status by conventional light microscopy possible. The primary goal of our study was to perform a CISH analysis following the method of Tanner et $a l^{16}$ with minor modifications. Using histological sections of formalin-fixed paraffin-embedded material, and a chromogenic detection system, we were able to identify HER-2/neu gene aberrations in $14 \%$ of our cases. The advantages of this assay are direct visualization of gene copies using a bright-field microscope, allowing simultaneous evaluation of the staining and morphology on the same slide, comparison with normal cell population as internal control, the requirement of very little tissue, and no additional equipment. On the other hand, this method can be criticized due to the inability to distinguish true gene amplification from aneusomy, since it does not include a specific probe for the chromosome 17-centromere. Therefore, to avoid this problem, we defined in analogy to the INFORM FISH assay (Ventana Medical Systems, Tucson, AZ, USA) gene amplification by an absolute HER2/neu gene copy number of $>5$ copies in at least $50 \%$ of tumour cells. ${ }^{16}$ Recently, Wang et al ${ }^{33}$ have indicated that, except in a certain subset of cases, aneusomy 17 probably is not a significant factor for HER-2/neu protein expression. However, McCormick et $a l^{34}$ have reported in a series of breast carcinoma that chromosome 17 polysomy is frequently associated with $(2+)$ overexpression by immunohistochemistry, suggesting that tumours scored at $(2+)$ should be analysed by a dual-probe FISH assay.

Our lower amplification rate detected by CISH assay $(14 \%)$ compared with those reported in the literature (17-63\%) may be due to the methodology (eg FISH, PCR, dot-blot hybridization), as well as the type of material (isolated nuclei, frozen sections). ${ }^{10,20,21,23}$ In a series of breast carcinoma, Tanner et $a l^{16}$ found that FISH (on fresh tissue), CISH, and immunohistochemistry (on paraffinembedded) correlated well. All tumours with amplification by CISH (17.2\%) were also amplified by FISH, but additional amplified cases were detected by FISH $(6.4 \%)$. However, CISH was performed on paraffin-embedded sections, which is technically more difficult than FISH on fresh frozen tissue. In our analyses performed on paraffin-embedded material for both assays, we detected two additional amplified cases by FISH among those with $(2+)$ overexpression but without amplification by CISH, reaching a final rate of amplification of $17 \%$ of the tumours. This suggests that CISH may have a lower sensitivity.

It is noteworthy that Tubbs et $a 1^{15}$ have recently described a technique that allows the simultaneous analysis of HER-2/neu copy number by FISH and protein by using a versatile alkaline phosphatase chromogen visible in either fluorescence or brightfield mode.

Gene amplification correlated significantly with protein expression in our cases, especially in tumours containing 10 or more copies per nucleus. Based on the observation that amplification can be seen in cases $(2+)$, we suggest that the combination of immunohistochemistry and CISH could be useful for the verification of status in inconclusive cases. Further FISH analysis by specialized laboratories can be recommended for $(2+)$ cases without amplification in CISH analysis.

Overall, protein overexpression in nonamplified tumours may represent examples of alterations of the mechanisms for gene expression, ${ }^{2,15,21,23}$ or may be due to the high sensitivity of the antibodies. ${ }^{14}$ Low-level amplification can be missed in thin histological sections as used in the present study, and may be below the detection level of the CISH assay. On the contrary, complete absence of protein expression in amplified tumours could be the result of an intrinsic feedback loop that limits the expression, as well as loss of tissue antigenicity. ${ }^{11,13,23}$ Low protein levels of HER-2/neu occasionally seen in normal cyclic and post-menopausal endometrium, with no gene amplification, may be the result of transcription activation.

HER-2/neu expression seems not to be associated with clinicopathologic factors and prognosis in endometrial carcinoma, which agrees well with the present data. ${ }^{10,19,21,22,24,25}$ However, opposite results have been reported..$^{18,23}$ Nevertheless, and in line with previous data, amplified tumours were more frequent among those of nonendometrioid type, high-grade, lymph-vascular invasion present and older age. ${ }^{23}$ Czerwenka et $a l^{10}$ observed amplification more frequently in complex and atypical hyperplasia than in simple hyperplasia, indicating a potential role in the development of some endometrial carcinomas.

In agreement with previous FISH studies, poor prognosis was seen for our patients with amplified tumours, with the highest levels being associated with the poorest prognosis. ${ }^{20,21,23}$ We observed groups of patients at different risk of death when they were stratified by stage of the disease, myometrial wall invasion, or lymph-vascular invasion. The data were still nearly significant when the classic clinicopathologic factors were considered in the multivariate analysis. Saffari et $a l^{20}$ reported that in those women, survival was improved by adjuvant treatment. In several tumour types, and especially in breast carcinoma, amplification of the HER-2/neu oncogene and overexpression of the protein have been also associated with adverse prognostic factors, and outcome, and they predicted the response to some chemotherapeutic regimens. ${ }^{2-5,7,8,13}$

The p53 tumour suppressor gene has been extensively studied in human neoplasia. Alteration of the gene (mutation or/and deletion) or protein accumulation occurs in over $50 \%$ of the cases. ${ }^{26}$ In 
the present series, overexpression of p53 was seen in $61 \%$ of the tumours. In previous series of endometrial carcinoma, the reported rate is quite variable (15-77\%), which may reflect the lack of consensus of the scoring methods among the studies. ${ }^{17,19,22,24,25,27,28}$ p53 overexpression has been observed in nonendometrioid type, oestrogen or progesterone receptor-negative tumours, advanced stages, and grade, and therefore associated with more aggressive phenotype. ${ }^{19,24,28}$ We found an association with advanced stages, but patients' prognosis was not different. ${ }^{22,27}$ Of note, Coronado et $a l^{25}$ reported worse prognosis in endometrial carcinoma patients whose tumours expressed both p53 and HER-2/neu. For Ito et al, ${ }^{27}$ mutation analysis defined more accurately a group of patients with worse prognosis.

It is well known that increased proliferation is responsible for tumour growth. Among proliferation markers, Ki-67 has been suggested to provide additional information regarding clinical course and prognosis. ${ }^{17,29,30}$ In agreement with previous series, we observed reactivity for $\mathrm{Ki}-67$ in half of our cases, which increased as age, FIGO grade and stage, and myometrial invasion progressed, ${ }^{28}$ and as a trend with nonendometrioid type and presence of lymph-vascular invasion. ${ }^{29}$ These findings point to a severe deregulation of the cell cycle in cases with more aggressive behaviour and, in fact, our patients had shorter survival. ${ }^{29,30}$ However, data on the prognostic relevance of Ki-67 in endometrial carcinoma are variable. ${ }^{28}$

Finally, although our HER-2/neu positive tumours (immunohistochemistry or CISH/FISH) contained frequently high levels of Ki-67 and accumulated p53, which would agree with their role in cell proliferation, ${ }^{17}$ the results did not reach significant correlation. ${ }^{22}$

In conclusion, our data suggest that HER-2/neu may play a role in the pathogenesis of a subset of endometrial carcinomas. CISH represents a new method of testing for HER-2/neu gene status, which is easy to perform on sections from the original specimen block used for diagnosis, and may complement the initial screening step by immunohistochemistry in routine clinical practice. An additional FISH assay is recommended for selected cases, such as tumours with $(2+)$ overexpression but negative CISH analysis. Although our approach will not eliminate completely false-positive or negative cases, it is suitable for most of the surgical pathology laboratories. In addition to clinicopathologic factors, the molecular characterization of HER2/neu gene status will help to predict the clinical behaviour, and it is of potential therapeutic interest.

\section{Acknowledgements}

We thank Mrs A Hirschmann, M Müller, and $S$ Heidrich for their technical assistance.

\section{References}

1 Schechter AL, Hung MC, Vaidyanathan L, et al. The neu gene: an erbB-homologous gene distinct from and unlinked to the gene encoding the EGF receptor. Science 1985;229:976-978.

2 Slamon DJ, Godolphin W, Jones LA, et al. Studies of the HER-2/neu Proto-oncogene in human breast and ovarian cancer. Science 1989;244:707-712.

3 Kakar S, Puangsuvan N, Stevens JM, et al. HER-2/neu assessment in breast cancer by immunohistochemistry and fluorescence in situ hybridization: comparison of results and correlation with survival. Mol Diagn 2000;5:199-207.

4 Heinze T, Jonas S, Karsten A, et al. Determination of the oncogenes p53 and c-erb B2 in the tumour cytosols of advanced hepatocellular carcinoma (HCC) and correlation to survival time. Anticancer Res 1999;19:2501-2503.

5 Kristiansen G, Yu Y, Petersen S, et al. Overexpression of c-erb B2 protein correlates with disease-stage and chromosomal gain at the c-erb B2 locus in non-small cell lung cancer. Eur J Cancer 2001;37:1089-1095.

6 Ross JS, Sheehan C, Heiner-Bucham AM, et al. Prognostic significance of HER-2/neu gene amplification status by fluorescence in situ hybridization of prostate carcinoma. Cancer 1997;79:2162-2170.

7 Press MF, Bernstein L, Thomas PA, et al. HER-2/neu gene amplification characterized by fluorescent in situ hybridization: poor prognosis in node negative breast carcinomas. J Clin Oncol 1997;15:2894-2904.

8 Slamon D, Leyland-Jones B, Shak S, et al. Use of chemotherapy plus a monoclonal antibody against HER2 for metastatic breast cancer that overexpresses HER2. N Engl J Med 2001;344:783-792.

9 Ross JS, Fletcher JA. HER-2/neu (c-erb B2) gene and protein in breast cancer. Am J Clin Pathol 1999;112: S53-S67.

10 Czerwenka K, Lu Y, Heuss F. Amplification and expression of the HER-2/neu oncogene in normal, hyperplastic, and malignant endometria. Int J Gynecol Pathol 1995;14:98-106.

11 Jacobs TW, Gown AM, Yazijy H, et al. Comparison of fluorescence in situ hybridization and immunohistochemistry for the evaluation of HER2/neu in breast cancer. J Clin Oncol 1999;17:1974-1978.

12 Lebeau A, Deimling D, Kaltz C, et al. HER-2/neu analysis in archival tissue samples of human breast cancer: comparison of immunohistochemistry and fluorescence in situ hybridization. J Clin Oncol 2001;19:354-363.

13 Hanna WM, Kahn HJ, Pienkowska M, et al. Defining a test for HER-2/neu evaluation in breast cancer in the diagnostic setting. Mod Pathol 2001;14:677-685.

14 Mass R, Sanders C, Charlene K, et al. The concordance between the clinical trials assay (CTA) and fluorescence in situ hybridization (FISH) in the Herceptin Pivotal Trials [abstract]. Proc ASCO 2000;19:75A.

15 Tubbs RR, Pettay J, Roche $\mathrm{P}$, et al. Concomitant oncoprotein detection with fluorescence in situ hybridization (CODFISH): a fluorescence-based assay enabling simultaneously visualization of gene amplification and encoded protein expression. J Mol Diagn 2000;2:78-83.

16 Tanner M, Gancberg D, Di Leo A, et al. Chromogenic in situ hybridization: a practical alternative fur fluorescence in situ hybridization to detect HER-2/neu 
oncogene amplification in archival breast cancer samples. Am J Pathol 2000;157:1467-1472.

17 Ioffe OB, Papadimitriou JC, Drachenberg CB. Correlation of proliferation indices, apoptosis, and related oncogene expression (bcl-2 and c-erb B2) and p53 in proliferative, hyperplasic, and malignant endometrium. Hum Pathol 1998;29:1150-1159.

18 Reinartz JJ, George E, Lindgren BR, et al. Expression of p53, transforming growth factor receptor, and c-erb B2 in endometrial carcinoma and correlation with survival and known predictors of survival. Hum Pathol 1994;25:1075-1083.

19 Pisani AL, Barbuto DA, Chen D, et al. HER-2/neu, p53, and DNA analyses and prognosticators for survival in endometrial carcinoma. Obstet Gycecol 1995;85:729-734.

20 Saffari B, Jones LA, el-Naggar A, et al. Amplification and overexpression of HER-2/neu (c-erb B2) in endometrial cancers: correlation with overall survival. Cancer Res 1995;55:5693-5698.

21 Riben MW, Malfetano JH, Nazeer T, et al. Identification of HER-2/neu oncogene amplification by fluorescence in situ hybridization in stage I endometrial carcinoma. Mod Pathol 1997;10:823-831.

22 Backe J, Gassel AM, Krebs S, et al. Immunohistochemically detected HER-2/neu expression and prognosis in endometrial carcinoma. Arch Gynecol Obstet 1997;259:189-195.

23 Rolitsky CD, Theil KS, McGaughy VR, et al. HER-2/neu amplification and overexpression in endometrial carcinoma. Int J Gynaecol Pathol 1999;18:138-143.

24 Heffner HM, Freedman AN, Asirwatham JE, et al. Prognostic significance of p53, PCNA, and HER-2/neu in endometrial carcinoma. Eur J Gynaecol Oncol 1999;20:8-12.

25 Coronado PJ, Vidart JA, López-Asenjo JA, et al. p53 overexpression predicts endometrial carcinoma recur- rence better than HER-2/neu overexpression. Eur J Obstet Gynecol Reprod Biol 2001;98:103-108.

26 Wolf HK, Stober C, Hohenfellner R, et al. Prognostic value of p53, p21/WAF1, Bcl-2, Bax, Bak, and Ki-67 immunoreactivityin pT1 G3 urothelial bladder carcinomas. Tumour Biol 2001;22:328-336.

27 Ito K, Sasano $\mathrm{H}$, Matsunaga $\mathrm{G}$, et al. Correlation between p21 expression and clinicopathological findings, p53 gene and protein alterations, and survival in patients with endometrial carcinomas. J Pathol 1997;183:318-324.

28 Salvesen HB, Iversen OE, Akslem LA. Prognostic significance of angiogenesis and Ki-67, p53, and p21 expression: a population-based endometrial carcinoma study. J Clin Oncol 1999;17:1382-1390.

29 Kallakury BVS, Ambros RA, Hayner-Buchan AM, et al. Cell proliferation-associated proteins in endometrial carcinomas, including papillary serous and endometrioid subtypes. Int J Gynecol Pathol 1998;17:320-326.

30 Geisler JP, Geisler HE, Miller GA, et al. MIB-1 in endometrial carcinoma: prognostic significance with 5-year follow-up. Gynecol Oncol 1999;75:432-436.

31 Kurman RJ, Zaino RJ, Norris HJ. Endometrial carcinoma. In: Blaustein's Pathology of the Female Genital Tract. Kurman RJ (ed). Springer-Verlag: New York, 1994; p 441.

32 FIGO stages: 1988 Revision. Gynecol Oncol 1989;35:125-127.

33 Wang S, Hossein Saboorian M, Frenkel EP, et al. Aneusomy 17 in breast cancer its role in HER-2/neu protein expression and implication for clinical assessment of HER-2/neu status. Mod Pathol 2002;15:137-145.

34 McCormick SR, Lillemoe TJ, Beneke J, et al. HER-2 assessment by immunohistochemical analysis and fluorescence in situ hybridization: comparison of HercepTest and PathVysion commercial assays. Am J Clin Pathol 2002;117:935-943. 